\title{
A Brief History of Piano Mechanics
}

\author{
Matteo RUSSO ${ }^{1}$ and Jose A. ROBLES-LINARES ${ }^{1}$ \\ ${ }^{1}$ Faculty of Engineering, University of Nottingham, Nottingham, UK \\ \{matteo.russo; jose.robleslinaresalvelais\}@nottingham.ac.uk
}

\begin{abstract}
The piano action mechanism transforms key motion into hammer swing, which creates sound by striking the strings. The mechanical design of the key action influences keyboard responsiveness, heaviness or lightness, which are critical playability parameters that can "make or break" an instrument for a pianist. From the rigid lever mechanism of $14^{\text {th }}$-century clavichords, key action mechanisms developed into the modern piano action, with dozens of bodies and compliant elements. This paper presents a brief history of this evolution, with an analysis of the most important designs from a technical perspective.
\end{abstract}

Keywords: History of Mechanism and Machine Science, Piano, Key Action.

\section{Introduction}

When a key is depressed, string keyboard instruments generate sound through a key action mechanism which plucks or strikes a string. The material, thickness, length, and tension of the string determine the pitch of the note that is generated, and a hollow resonating chamber or a soundboard amplify the sound, increasing its volume.

Even if keyboard musical instruments date back to Greek hydraulic organs (ca. $3^{\text {rd }}$ Century BC) [1], key action mechanisms were applied to string instruments only in the Late Middle Ages $\left(14^{\text {th }}\right.$ and $15^{\text {th }}$ Centuries) $[2,3,4]$, when struck-string clavichord [5] and plucked-string harpsichord [6,7] were invented. The harpsichord flourished during the Renaissance and Baroque eras, thanks to composers such as Georg Friedrich Händel (1685-1759) and Johann Sebastian Bach (1685-1750). Despite the wide range of harpsichord variants available in those years (e.g. virginal, spinet, twomanual), they mostly shared the same action, with the key acting as a lever to lift a jack with a small wedge-shaped end-effector (plectrum), which plucks the string [7].

A pivotal year is 1700, when harpsichord maker Bartolomeo Cristofori (16551731) invented the fortepiano while working for the House of Medici [8]. This struckstring piano has significant mechanical improvements: multiple levers are added to amplify key motion; the hammer is guided halfway to the string, travelling the remaining distance with momentum (enabling dynamics such as forte and piano); a side linkage is included for damping [4]. Despite its complexity, the rich sound and dynamics of the fortepiano immediately appealed to composers such as Joseph Haydn (1732-1809), Wolfgang Amadeus Mozart (1756-1791) and Ludwig Van Beethoven (1770-1827), who boosted the success of the piano until the harpsichord all but disap- 
peared [3]. The key action mechanism in modern upright and grand pianos keeps the main concepts of Cristofori's original design but has been modified through the centuries to improve robustness, responsiveness and performance in rapidly repeated notes [9-11].

The 1950s marked another turning point with the development of electromechanical keyboard instruments, which forego soundboards for electric amplification $[12,13]$. Some of these electric pianos used grand/upright mechanisms with hammered strings (e.g. Yamaha CP70), while others replaced strings with metal reeds (e.g. Wurlitzer) or tines (e.g. Fender Rhodes) [14]. These instruments were brought to fame by jazz, pop and rock musicians such as Duke Ellington, Ray Charles and The Doors. A different key action was used for the clavinet (1970s), an electro-mechanical keyboard inspired by the clavichord, widely used by Stevie Wonder and Billy Preston among others [15]. In the 1980s, the rise of synthesizers [16], which generate sounds through the analog or digital synthesis of soundwaves and filters, led to the development of a new action with light spring-loaded keys (synth action). Hybrid design with both springs and weights, called semi-weighted actions, were also developed for improved responsiveness [17].

This paper analyzes the evolution of piano mechanisms over the past six centuries. First, three examples of historic keyboard actions are introduced with the clavichord, the harpsichord and the fortepiano. Their functioning and influence on current designs are discussed. Then, modern grand and upright actions are presented with technical details. Finally, recent developments in electro-mechanical keyboard and synth actions are reviewed to reveal the current trends and foresee possible future developments.

\section{Evolution of Piano Mechanics}

Clavichord. The clavichord action is a simple key lever with a hammer on one end, as in Fig. 1a. This mechanism, described in Table 1, is characterized by greater expressivity than most other keyboard instruments, by enabling volume dynamics, vibrato and control over sound attack and duration. This action, however, leaves limited space for a soundboard, and the extremely low volume of this instrument, together with always-on passive string damping, relegated it mostly to private use, while the harpsichord enjoyed its fame as a concert instrument.

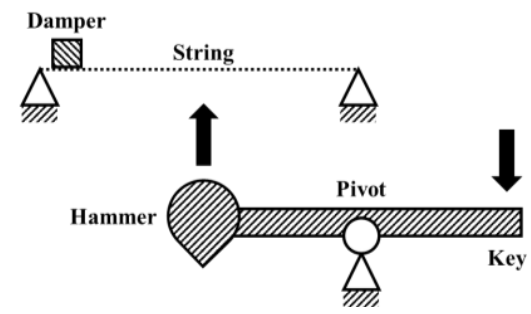

a)

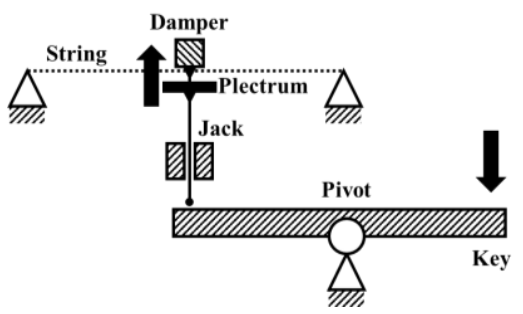

b)

Fig. 1. Simplified kinematic schemes of historical key actions: a) Clavichord; b) Harpsichord. 
Table 1. Clavichord key action.

\begin{aligned} & \hline Step Action \\ & \hline 1 The key is depressed, immediately lifting the hammer on the other side of the lever. \\ & 2 The hammer hits the string, staying in contact with it. \\ & 3 When the key is released, the hammer goes down. \\ & \hline\end{aligned}

Harpsichord. The harpsichord action is based on a single lever transmission, as in Fig. 1b. When depressed, the key lifts a jack that plucks the string with its plectrum and contains also a damper that lets the string resonate, as explained in Table 2. The expressivity of the harpsichord is limited when compared to the clavichord: there is almost no volume dynamics, and vibrato cannot be performed. However, the on/off string damping and higher volume (due to multiple strings and larger soundboards) made the harpsichord more successful than the clavichord until pianos replaced both.

Table 2. Harpsichord key action.

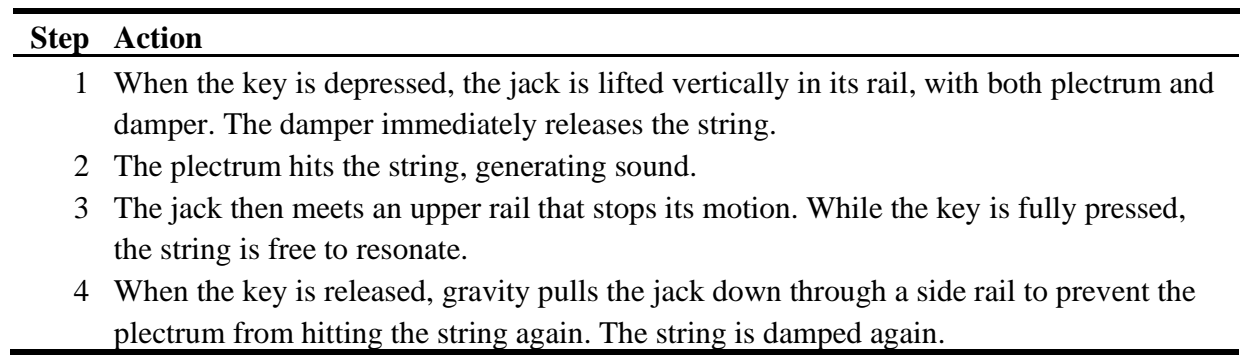

Fortepiano. Cristofori's design, often called fortepiano, introduces sweeping changes by adding additional levers to improve motion transmission, by guiding the hammer only partially to the string and by implementing a damping mechanism as explained in Table 3. The fortepiano, shown in Fig. 2, is characterized by a large soundboard, which gives it a good volume and a full sound rich in harmonics. The improved control over the damper and the momentum-driven hammer enable expressivity with both volume and tone dynamics. The introduction of a pedal that lifts all dampers independently from the keyboard also lets all the strings resonate while keys are released.

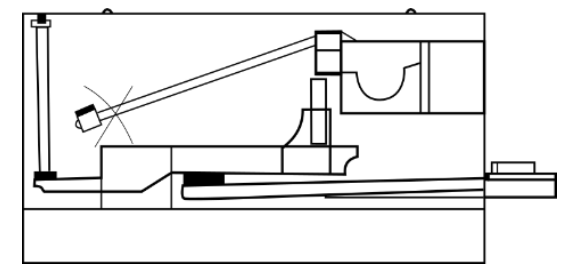

a)

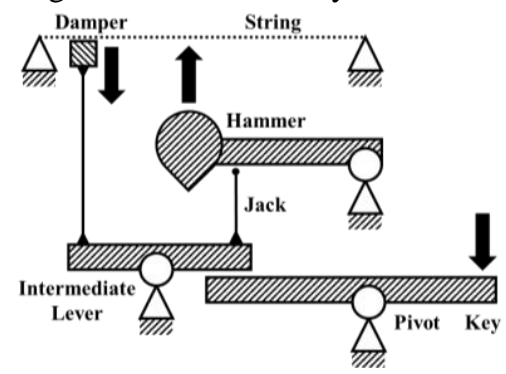

b)

Fig. 2. Fortepiano key action: a) Cross-section view from an $18^{\text {th }}$-century drawing [4]; b) A simplified kinematic scheme. 
Table 3. Fortepiano key action.

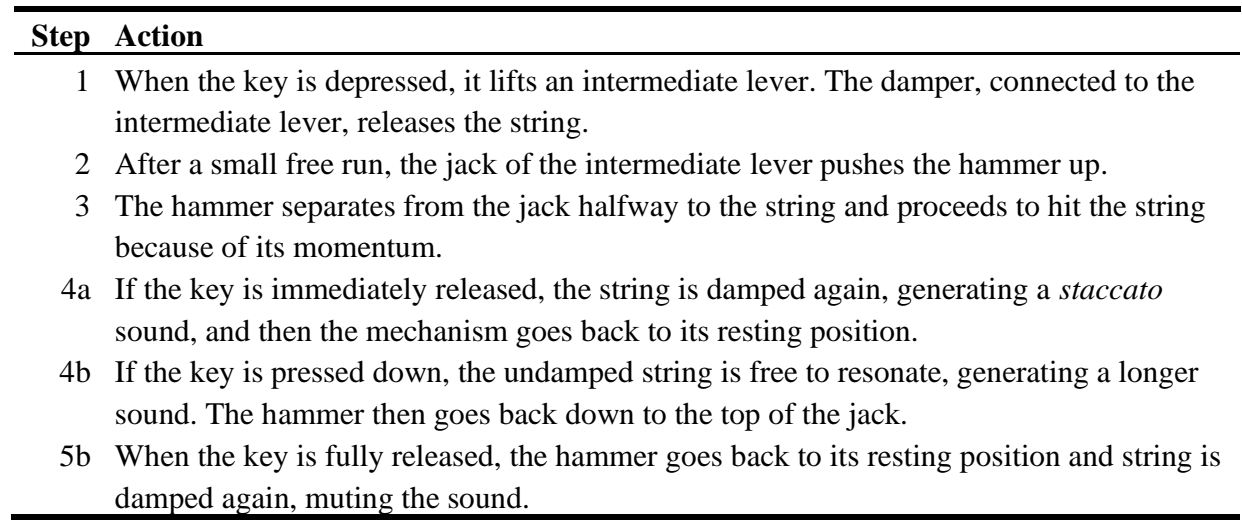

\section{$3 \quad$ Modern Piano Mechanics}

Piano usage was boosted by the significant contributions of great composers, such as Mozart and Beethoven, during the late $18^{\text {th }}$ and early $19^{\text {th }}$ centuries. This, together with the novel production and manufacturing capabilities of the Industrial Revolution (1760-1840), fueled a demand for improved pianos with richer sound and increased stability, robustness and sensitivity. Modern acoustic pianos maintain the main functioning principle of the fortepiano but are characterized by changes that improve sound quality and overall performance, especially for rapidly repeated notes to favor the pianists' execution. Modern pianos can be upright pianos, with a compact frame that suits domestic use or practice rooms; or grand pianos, with a larger soundboard that fits performance venues and concert halls due to their brighter and richer sound.

Grand Piano. As shown in Fig. 2, the intermediate lever of a fortepiano is attached to both damper and jack. On the contrary, the grand piano action, in Fig. 3, has an independent damping mechanism where the damper is lifted only halfway through hammer run when the key is depressed. This action, detailed in Table 4, is also characterized by a repetition lever that allows to repeat a note even if the key is not fully released. This lever made a breakthrough in piano history by enabling fast note repetition for both soft (piano) or heavy (forte) notes.

Upright Piano. Upright pianos are comparable to grand pianos in action complexity and mechanism, with the vertical string layout shown in Fig. 4 and lack of a repetition lever as main differences. The upright piano action functioning is described in Table 5. This design offers the advantage of reduced encumbrance and lower cost. However, its shorter strings and smaller soundboard result in a lower sound quality than grand pianos and the lack of a repetition lever can limit professional pianists in execution. 
Table 4. Grand piano key action.

\begin{aligned} & \hline Step Action \\ & \hline 1 The key is depressed, immediately lifting the wippen and the jack. The latter pushes on \\ & the knuckle and the hammer starts moving upwards. \\ & 2 When the hammer is halfway to the string, the extremity of the key lever starts pushing \\ & the damper upwards, releasing the string. \\ & 3 Slightly before the hammer hits the strings, the jack reaches its motion limit when its toe \\ & is constrained by the letoff button. \\ & 4 The hammer continues moving upwards only by inertia, until it hits the string and re- \\ & bounds back. \\ & 5 During the rebound motion, the hammer goes downward, but the knuckle lands on the \\ & spring-loaded rebound lever instead of the jack, kept down by the letoff button. \\ & 6 The hammer's downward inertia pushes the repetition lever down, and the hammer tail \\ & is caught and held in place by the backcheck. \\ & 7 If the key is still depressed, the string is free to resonate. \\ & 8 a If the key is slightly (not fully) released, the backcheck releases the hammer tail and the \\ & repetition lever moves the jack back under the knuckle, enabling a new full cycle with- \\ & out the key being fully released. This part of the mechanism allows fast-repeated notes \\ & to be played. \\ & $8 b$ When the key is fully released, the hammer falls back into its rest place, the jack returns \\ & to its rest position under the knuckle, and the string is damped. \end{aligned}

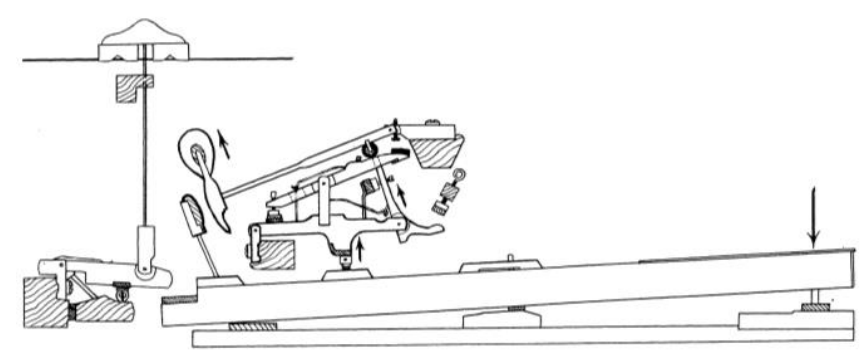

a)

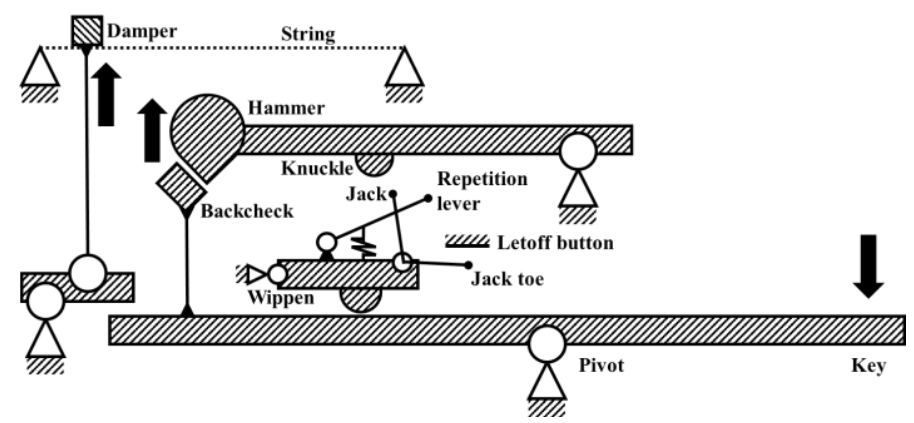

b)

Fig. 3. Grand piano key action: a) Cross-section view [10]; b) A simplified kinematic scheme. 
Table 5. Upright piano key action.

\begin{aligned} & \hline Step Action \\ & \hline 1 When key is depressed, the wippen rotates, moving the jack upwards while compressing \\ & the jack spring. The hammer starts to move. \\ & 2 The wippen's left end actuates the damper lever, lifting the damper off the string. \\ & 3 The jack reaches its motion limit point when constrained by the letoff button. Thus, the \\ & jack disengages from the hammer. \\ & 4 The hammer continues to move by inertia and hits the string. \\ & 5 The hammer rebounds until it gets caught by the backcheck. \\ & 6 If the key is still depressed, the string is free to resonate. \\ & 7 When the key is fully released, the hammer falls back into its rest place, the jack returns \\ & to its rest position and the string is damped. \end{aligned}

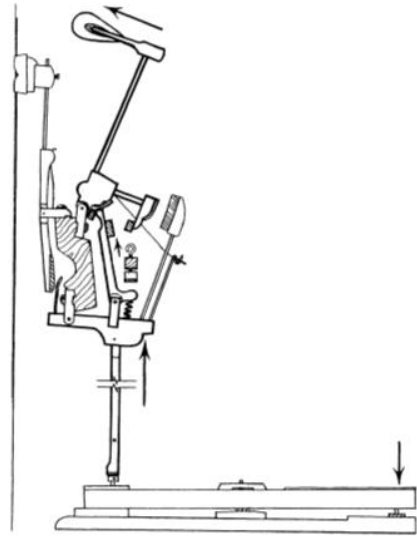

a)

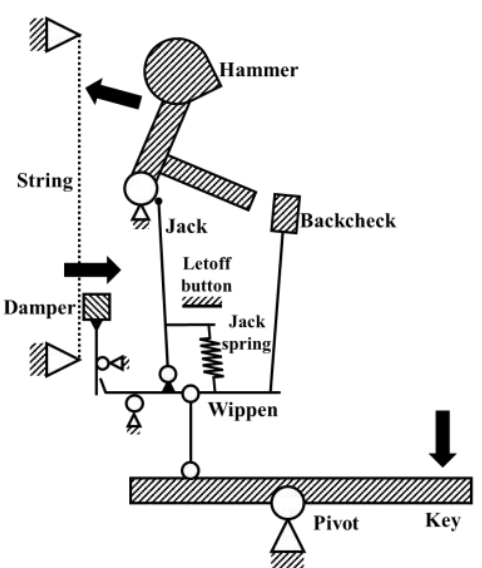

b)

Fig. 4. Upright piano key action: a) Cross-section view [10]; b) A simplified kinematic scheme.

\section{$4 \quad 20^{\text {th }}$-century Keyboards}

Electro-mechanical keyboards. Several electro-mechanical keyboard instruments were developed during the $20^{\text {th }}$ Century. The main difference between an electromechanical and an acoustic instrument is the soundboard: while acoustic instruments use a resonance chamber to amplify the sound and enrich it with harmonics, electromechanical instruments acquire the soundwave vibration through a pickup and amplify it electrically. Most electric pianos use fortepiano, grand or upright mechanisms, sometimes replacing strings with reeds or tines. For example, the Fender Rhodes key action shown in Fig. 5 is based on the kinematic scheme in Fig. 2b. The clavinet is based on the clavichord mechanism in Fig. 1a. Despite the different functioning and sound of electro-mechanical keyboards, the key action presents no significant change. 


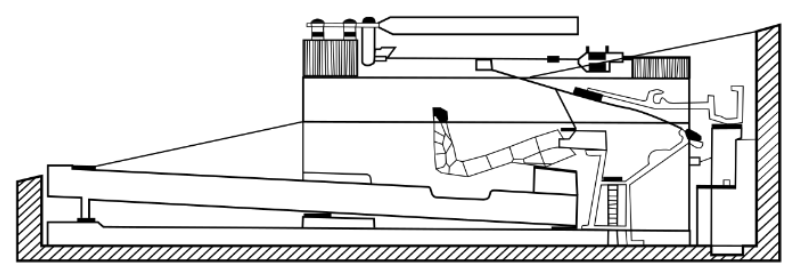

Fig. 5. Fender Rhodes key action [18].

Synthesizers. Modern synthesizers (synths) require a new approach to action mechanisms: instead of generating sounds by striking or plucking strings, reeds or tines, they depend on electronics for analog or digital soundwave generation and processing. Thus, synth keys need to generate numerical values such as ON/OFF signals or velocity signals, which are integers between 1 and 127 under standard MIDI protocol. For this reason, a single lever with an electronic sensor is enough, with a spring (sometimes with added weight) to return the key up after release, as shown in Fig. 5. This mechanism, detailed in Table 6, is independent from gravity, enabling vertical keyboard layouts. Furthermore, synth action is extremely affordable, lightweight and compact. Its mechatronic nature, however, can limit the expressivity of the instrument, even if additional tools are often added to compensate (e.g. pitch bend and modulation levers, aftertouch sensors, low frequency oscillators, ADSR parameters, filter cutoff and resonance knobs [16]).

Table 6. Synth key action.

Step Action

1 When the key is depressed, it rotates around the pivot point up to its limit.

2 A velocity sensor measures key velocity and transmits the information as a MIDI message to the sound generation unit.

3 While key is pressed down, the sensor keeps sending the MIDI signal without changing the velocity value.

4 When the key is released, the signal stops and the spring pushes the key back to its resting position.

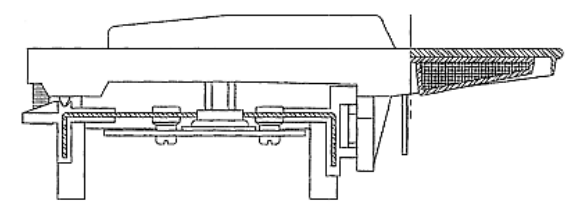

a)

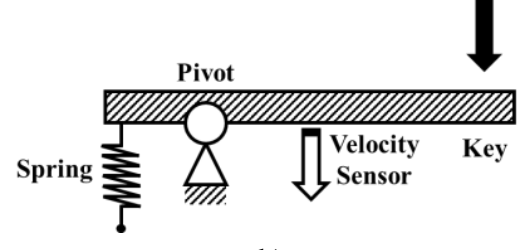

b)

Fig. 6. Synth key action: a) Cross-section view of FATAR TP 9S keybed, [17]; b) A simplified kinematic scheme. 


\section{Conclusions}

The evolution of piano action mechanisms was reported chronologically through the clavichord, harpsichord, fortepiano, grand piano, upright piano, electro-mechanical keyboard and synthesizer. Their kinematics and functioning were explained, and their advantages and drawbacks were identified from both a technical and artistic standpoint. Overall, piano mechanics breakthroughs resulted from two major factors: technological advancements and demand for sound quality. Initially, the evolution from one piano mechanism to another was ruled by the need for improved volume until the $17^{\text {th }}$ century, leading to the development of the fortepiano. Then, during the $17^{\text {th }}$ and $18^{\text {th }}$ centuries, the Industrial Revolution enabled the production of more complex mechanisms that favored dynamics and responsiveness, and so grand and upright pianos were born. In the $20^{\text {th }}$ century piano mechanisms have stagnated with no significant design changes in key action, because analog and digital instruments fulfilled the rising demand for new sounds as well as the need for cheaper alternatives. Current development trends focus on enhancing the expressivity of music performance through mechatronics and digital tools rather than mechanical improvements.

\section{References}

1. MacLean, C.: The Principle of the Hydraulic Organ. Franz Steiner Verlag (1905).

2. Bie, O.: A history of the pianoforte and pianoforte players. JM Dent (1899).

3. Dolge, A.: Pianos and their makers: a comprehensive history of the development of the piano from the monochord to the concert grand player piano. Courier Corporation (1972).

4. Isacoff, S.: A natural history of the piano: the instrument, the music, the musicians--from Mozart to modern jazz, and everything in between. Knopf (2011).

5. Brauchli, B.: The clavichord. Cambridge Univ. Press (1998).

6. Kroll, M.: Cambridge Companion to the Harpsichord. Cambridge Univ. Press (2019).

7. Bond, A.: A Guide to the Harpsichord. Hal Leonard Corporation (2003).

8. Badura-Skoda, E.: The Eighteenth-Century Fortepiano Grand and Its Patrons: From Scarlatti to Beethoven. Indiana Univ. Press (2017).

9. Askenfelt, AG, Jansson, EV.: Piano touch, hammer action, and string motion. The Journal of the Acoustical Society of America, 71S1:S92 (1982).

10. Reblitz, AA.: Piano Servicing, Tuning, and Rebuilding. Rowman \& Littlefield (2019).

11. Rowland, D., Cross, J.: Cambridge companion to the piano. Cambridge Uni. Press (1998).

12. Roads, C.: Early electronic music instruments: Timeline 1899-1950. Computer Music Journal 20(3) (1996).

13. Parakilas, J.: Piano roles: A new history of the piano. Yale Univ. Press (2002).

14. Shear, G., Wright, M.: The electromagnetically sustained Rhodes piano. NIME Proceedings, Oslo (2011).

15. Remaggi, L., Gabrielli, L., de Paiva, R.C., Välimäki, V., Squartini, S.: A pickup model for the Clavinet. Proceedings of the 15th Conference on Digital Audio Effects, York (2012).

16. Vail, M.: The synthesizer: a comprehensive guide to understanding, programming, playing, and recording the ultimate electronic music instrument. Oxford Univ. Press (2014).

17. FATAR website, http://www.fatar.com/, last accessed 2020/02/05.

18. Rhodes Keyboard Instruments U.S.A.: Service Manual (1979). 